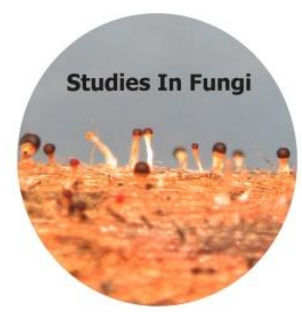

Studies in Fungi 2 (1): 171-177 (2017) www.studiesinfungi.org ISSN 2465-4973

Article

Doi 10.5943/sif/ 2/1/19

Copyright $\odot$ Mushroom Research Foundation

\title{
Myxomycetes occurring on selected agricultural leaf litters
}

\author{
Redeña-Santos $\mathrm{JC}^{1 *}$, Dunca JAU ${ }^{1}$, Thao $\mathrm{DV}^{1}$ and Dagamac $\mathrm{NHA}^{2}$ \\ ${ }^{1}$ Thai Nguyen University of Agriculture and Forestry, Quyết Thắng, Thái Nguyên, Vietnam \\ ${ }^{2}$ Institute of Botany and Landscape Ecology, Ernst - Moritz - Arndt Universität Greifswald, Soldmannstrasse 15, D- \\ 17487 Greifswald, Germany
}

Redeña-Santos JC, Dunca JAU, Duong VT, Dagamac NHA 2017 - Myxomycetes occurring on selected agricultural leaf litter. Studies in Fungi 2(1), 171-177, Doi 10.5943/sif/2/1/19

\begin{abstract}
Although studies of myxomycetes (plasmodial slime moulds) in the Asia Pacific region have been remarkable for the past years, studies about myxomycetes assemblages in association with homogenous vegetation are relatively few. In an effort to investigate further about myxomycetes assemblages in monotypic vegetation, the present study was carried out in three different agricultural plantations (Camellia sinensis (L.) Kuntze., Dimocarpus longan Lour., Psidium guajava L.). Ninety percent (90\%) of the moist chamber cultures gave a total of 165 records (107 determinable fruiting bodies and 58 plasmodial records). From these records, 20 myxomycetes morphospecies composed of 17 clear-cut species and three varieties of the species Arcyria cinerea were recorded. The occasionally reported myxomycetes species Physarum tenerum in other Southeast Asian countries seems to be abundantly occurring for the agricultural litters in Vietnam. This study noted that agricultural leaf litter substrates with leathery leaf texture can serve as spore traps for myxomycetes that are dispersing in the environment. Hence, agricultural litters are good microhabitat for many known cosmopolitan myxomycetes. This is the first report of myxomycetes assemblages associated with Camellia sinensis, Dimocarpus longan and Psidium guajava leaf litters.
\end{abstract}

Key words - foliicolous - moist chamber - occurrence - slime molds - tropical plants - Vietnam

\section{Introduction}

Since myxomycetes are known to be on ecosystems where there is a high decaying organic plant material such as leaf litter, they are considered to play an important role in nutrient cycling of forest detritus (Rayner \& Boddy 1988). This is probably the reason why much of the previous reports regarding the distribution of foliicolous myxomycetes in Asia were described from diversity studies conducted mainly on forest floor litters. Examples of which were the exhaustive studies in temperate Japan that investigated myxomycete communities between deciduous broadleaf and evergreen tree leaf litters (Takahashi 2013, Takahashi 2015) or the recent studies in near natural lowland forest pockets on scattered islands of the Philippines that addresses the geographic distribution of myxomycetes in Southeast Asia using ground leaf litter (Macabago et al. 2016, Dagamac et al. 2015a). Other ecosystems i.e. ultramafic and volcanic soils (Rea-Maminta et al. 2015) and vegetation types i.e. grasslands (Carascal et al. 2017), reef woodland (Macabago et al. 2017) have been recently reported for the occurrence of foliicolous myxomycetes in the tropical Southeast Asia. 
In spite of the fact that the major economic resources in Southeast Asia are coming from agriculture, there is relatively limited information about foliicolous myxomycetes that associate it with monotypic vegetation like an agricultural plantation which could also serve as an ideal source of leaf litter substrates. Thus, this study is intended to discover leaf litter inhabiting myxomycetes on three widely farmed agricultural plants in Thai Nguyen City, Northern Vietnam, namely the green tea (Camellia sinensis), longan (Dimocarpus longan) and guava tree (Psidium guajava).

The present study is conducted to expand the current knowledge about the potential of some tropical plants to serve as a microhabitat for the growth and development of myxomycetes. The significance of this study does not only serve as the first report of myxomycetes associated with the aforementioned agricultural plants but also will help to establish the initial information for comprehensive ecological studies regarding the distribution of myxomycetes in agricultural lands of Southeast Asia.

\section{Materials \& Methods}

\section{Collection of substrates and preparation of moist chambers}

Aerial leaf litters (AL) and ground leaf litter (GL) substrates were randomly collected from three different agricultural plantations (Camellia sinensis, Dimocarpus longan, and Psidium guajava) in Thai Nguyen City (21 $\left.35^{\prime} 39.19^{\prime \prime} \mathrm{N}, 105^{\circ} 50^{\prime} 53.41^{\prime \prime} \mathrm{E}\right)$, a municipality situated in the Northeast region of Vietnam (Fig. 1).

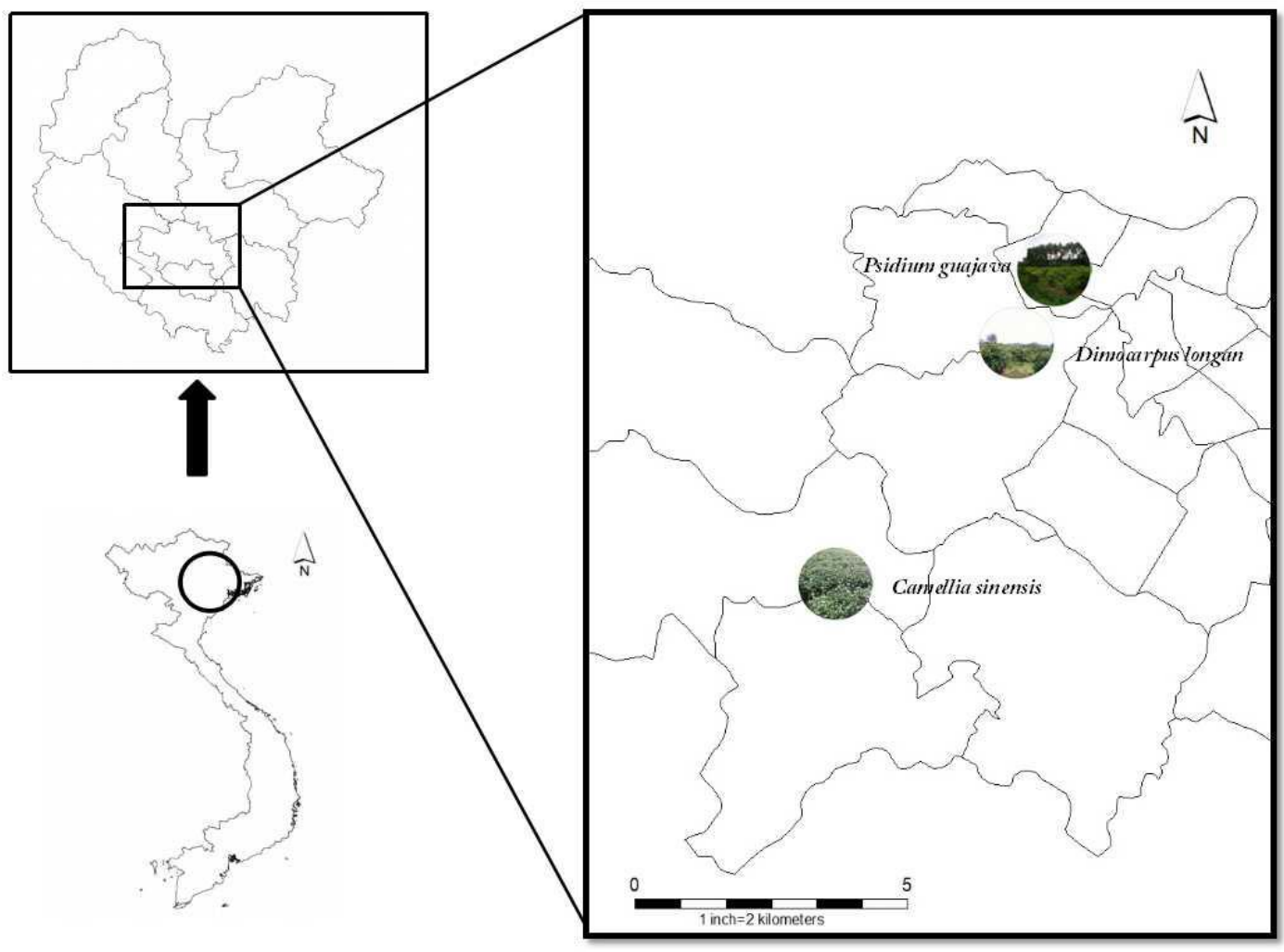

Fig. 1 - The study area: Thai Nguyen City, Thai Nguyen Province showing the sampling location of the three agricultural plantations.

Three $5 \times 5 \mathrm{~m}$ plots were initially established for each agricultural plantation. Five samples of AL and GL were then randomly collected for each plot making a total now of 15 AL and 15 GL per agricultural plantations. All of the collected substrates were initially placed inside dry paper bags 
and were then immediately transported in the laboratory. The moist chamber (MC) cultures were set up following the protocol of Stephenson \& Stempen (1994). The MCs were then soaked overnight in sterile distilled water. After 24 hours, the $\mathrm{pH}$ of each substrate was checked 3 times with a $\mathrm{pH}$-meter and was maintained under ambient light conditions, at room temperature $\left(22-25^{0}\right.$ C) for up to 10 weeks. The MCs were regularly checked every week for the presence of myxomycetes plasmodia and/or fruiting bodies. To keep the MCs moist, distilled water was added in certain occasions.

\section{Characterization and identification of fruiting bodies}

Moist chambers that produced myxomycetes fruiting bodies were initially segregated. The substrates inside those moist chambers were then placed inside herbarium matchboxes and were cooled under freezing condition overnight. The fruiting body characteristics (type, shape, presence of lime, height, color) were then described and were used for initial determination using a stereo microscope (Zeiss Stemi DV4). Internal structure of the fruiting bodies was also noted such as presence or absence of columella, appearance of the hypothallus, attachment to the calyculus and layers of peridium. Microscopic characterizations of the fruiting bodies were also conducted by carefully transferring a single fruiting body on a slide with a drop of Hoyer's medium. After 24 hours, the mounted slides were viewed using a light compound microscope (Zeiss Axiolab A1). Structures such as the spore (size, appearance, color) and capillitium (morphology, presence of free ends) were then characterized to verify the identity of a fruiting body. The specimens were then determined using published literatures (Poulain et al. 2011) and with web-based identification key (http://slimemold.uark.edu/). Current names were counter-checked using an online nomenclatural database for the eumycetozoans (http://nomen.eumycetozoa.com). For specimens that could not be fully identified with strong certainty due to some malformations but with distinguishing character enough to separate it as a species, the abbreviation "cf" was used in the taxon name. All vouchers of collected specimens were deposited under the private collection of the last author in the Institute of Landscape Ecology and Botany, Greifswald University.

\section{Calculation of productivity and myxomycetes occurrence}

The productivity of the moist chambers for each agricultural plantation was generated in accordance to the calculation of the percentage yield of Dagamac et al. (2012). A moist chamber that exhibited either plasmodial and/or fruiting body growth was considered as positive record for myxomycetes and therefore, was noted as one positive collection. For all of the myxomycetes collected in this study, an abundance index was used following the categories of Stephenson et al. (1993) which is based upon the proportion of a species to the total number of records: $\mathrm{R}-$ rare (< $0.5 \%)$, O-occasional (> 0.5-1.5\%), C-common (> 1.5-3\%), A-abundant (>3\%).

\section{Results}

A total of $90 \%$ moist chambers were positive for myxomycetes (either plasmodia/fruiting bodies) wherein leaf litters from Dimocarpus longan yielded the most number of positive moist chamber cultures (63) among the three agricultural plantations. This is headed by Psidum guajava and Camelia sinensis with 51 and 50 positive moist chambers, respectively (Table 1). The distribution of moist chambers that yielded myxomycetes among the substrates showed relatively equal percentages between the aerial and ground litter substrates for the three plant species. Our result (Fig. 2a) showed that Camelia sinensis had 48-52, Dimocarpus longan gave 50-50 and Psidum guajava generated 42-58 of aerial litter-ground litter percentage yields.

A total of twenty (20) myxomycetes morphospecies comprising of 17 species and three varieties of the species Arcyria cinerea (see Dagamac et al. 2017) were collected for this study (Table 1). Of these, 38\% belong to the Superorder Lucisporidia (bright-spored) and $72 \%$ are species coming from the Superorder Fuscisporidia (dark-spored). The breakdown of percentage yields among the three agricultural plants that consider both Superorders also showed higher result for the dark-spored than the bright-spored (Fig. 2b). In terms of occurrence (Table 1), six were 
Table 1 Occurrence of myxomycetes: The table shows the list of myxomycetes and their average $\mathrm{pH} \pm$, min - max values as measured on every positive moist chamber. A species recorded as rare (1 record) uses only the $\mathrm{pH}$ value of the sole moist chamber where it was found. The color on the left side of the species indicates their Superorder (yellow=bright-spored, Superorder Lucisporidia; brown=dark-spored, Superorder Fucisporidia). The abundance index (AI) in accordance to Stephenson et al. (2013), and their total number of records is further reported on this table. The distribution of records for substrates (AL or GL) and agricultural plants are also enumerated.

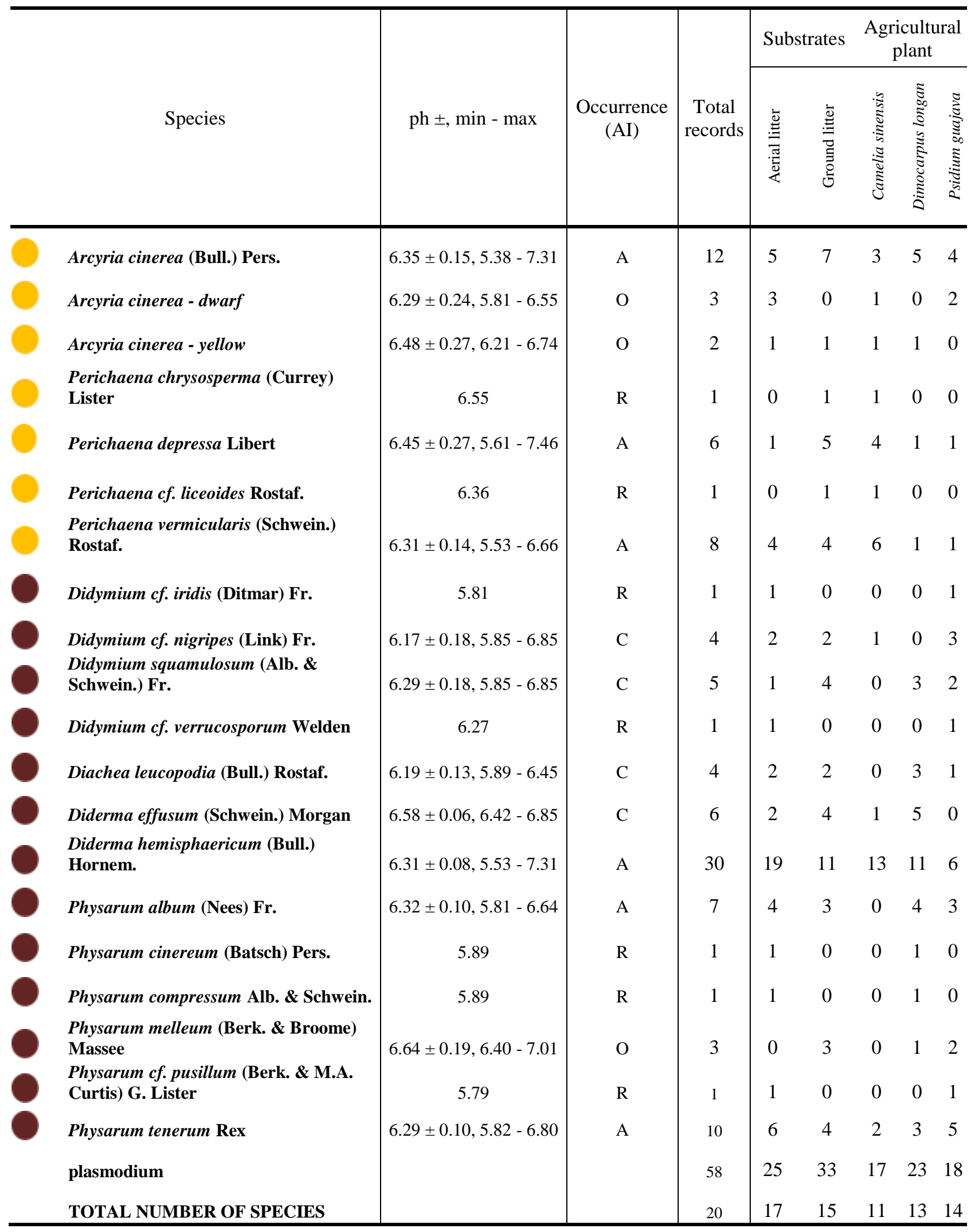


abundant (Arcyria cinerea, Perichaena depressa, Per. vermicularis, Diderma hemisphaericum, Physarum album, Phy. tenerum), four were common (Didymium cf. nigripes, D. squamulosum, Diachea leucopodia, Did. effusum), three were occasionally occurring (Arc. cinerea-yellow, Arc. cinerea-dwarf, Phy. melleum) and seven were recorded as rare (Per. chrysosperma, Per. cf. liceoides, D. cf. iridis, D. cf. verrucosporum, Phy. cinereum, Phy. compressum and Phy. cf. pusillum).

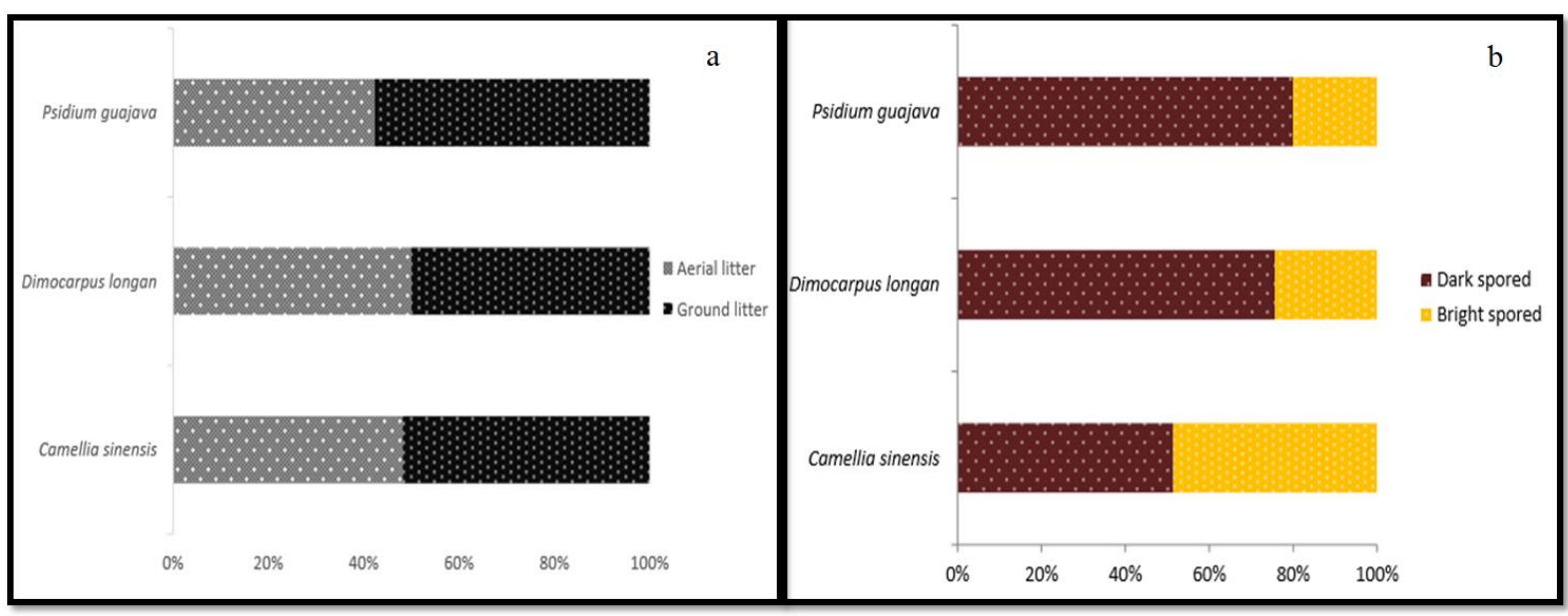

Fig. 2 - The 2D bar graph shows (a) percentages of positive moist chambers between the aerial (AL) and ground leaf (GL) litter substrates in three different agricultural plantations and (b) percentages showing the distribution of all the records between Superorder Lucisporidia (brightspored) and Superorder Fuscisporidia (dark-spored) in three different agricultural plantations.

\section{Discussion}

Because most of the myxomycetes studies in Southeast Asia are concerted more on vegetation with high plant heterogeneity such as lowland natural forest (Novozhilov et al. 2017, Dagamac et al. 2017), coastal forest (Macabago et al. 2012) or protected landscapes (Pecundo et al. 2017, Dagamac et al. 2015b), studies about associations of myxomycetes in monotypic vegetation are apparently still limited. Through this study, our result showed that in spite of homogenous distribution of plants like in an agricultural plantation, the organic decaying leaf litter substrates found either still not in contact or directly lying on the ground can harbour at least cosmopolitan myxomycetes. This was evident both from the higher moist chamber productivity that yielded a total of $90 \%$ and higher myxomycetes occurrence that produced 165 records. Moreover, from the 165 records collected in this study, most of the positive moist chambers were able to generate successful development of fruiting bodies (107). Comparing the two leaf litter substrates type, the aerial litter yielded a higher number of species than ground litter. This concurs with many studies that proofs that in tropical moist chambers, aerial litters have richer diversity of species because of the differences on the level of moisture availability (Schnittler \& Stephenson 2002, Rojas et al. 2014).

The composition of myxomycetes among the three agricultural plantations seems to be relatively similar with the highest number of species recorded from samples of Psidium guajava This result is comparatively higher than the investigation conducted by Alfaro et al. (2015) from Saccharum officinarum litters collected from the Philippines that only gave $18 \%$ moist chamber productivity with only 2 species. Perhaps, this could be attributed to the leaf textures of the plant species and their potential to catch and trap dispersed myxomycetes spores in their immediate environment. Since Saccharum officinarum has a smooth and hairless leaf surface, it is likely that spores easily slide on the surfaces of its leaf. On the other hand, Dimocarpus longan and Psidium guajava both have thick leathery leaves and Camellia sinensis has been characterized to have white hairs underside its leaf which can serve as spore traps particularly on myxomycete spores that have ornamentation like warts and spines. 
In terms of the proportion of dark-spored myxomycetes and bright-spored myxomycetes in the moist chambers, the results we gained further ascertain other previous study that points out the higher records of dark-spored myxomycetes in leaf litters for monotypic vegetation (Macabago et al. 2017, Carascal et al. 2017). The occurrences of the myxomycetes reported on the three agricultural plantations confirms the broad range distribution of some myxomycetes that were reported in other specific substrates like Arcyria cinerea in Attalea speciosa Mart. ex Spreng (Parente \& Cavalcanti 2013), Diderma hemisphaericum in Mangifera sp. (Tran et al. 2008) and Diderma effusum in Musa sp. (Tran et al. 2008). Furthermore, it is interesting to note that the occasionally reported myxomycetes species Physarum tenerum in other Southeast Asian countries seems to be abundantly occurring for the agricultural leaf litters in Vietnam.

Considering now the amount of records generated in this small scale survey for agricultural plantations, it seems that agricultural leaf litters can serve as a good microhabitat for myxomycetes. Thus, this study reports for the first time myxomycetes associated on Camelia sinensis, Dimocarpus longan and Psidium guajava. This now implies that it would be noteworthy to expand myxomycetes diversity studies on monotypic vegetation in the future since there are a lot of tropical agricultural plants that are planted and cultivated in many countries in Southeast Asia that may carry undiscovered species of myxomycetes.

\section{Acknowledgements}

JCR-S would like to acknowledge Prof. Martin Schnittler (Director, Institute of Botany and Landscape Ecology) and the International Office of the University of Greifswald for the 3 months research scholarship. The authors would like to also thank the SusEnMan (Sustainable Environmental Management) Project headed by Prof. Dr. Wilhelm Steingrube for the grant given for the field collection. We would also like to acknowledge Ha Hong, Oriana Sanchez-Mahecha, Linh Thuy Nguyen, Israel Ponce, and Vu Thi Thao for their technical assistance.

\section{References}

Alfaro JRD, Alcayde DLIM, Agbulos JB, Dagamac NHA et al. 2015 - The occurrence of myxomycetes from a lowland montane forest and agricultural plantations of Negros Occidental, Western Visayas, Philippines. Fine Focus 1, 7-20.

Carascal MB, Rea MAD, Dagamac NHA, dela Cruz TEE. 2017 - Myxomycetes associated with grassland litter in the Philippines. Current Research in Environmental and Applied Mycology 7, 56-63.

Dagamac NHA, Stephenson SL, dela Cruz TEE. 2012 - Occurrence, distribution, and diversity of myxomycetes (plasmodial slime molds) along two transects in Mt. Arayat, National Park, Pampanga, Philippines. Mycology 3, 119-126.

Dagamac NHA, Rea-Maminta MAD, dela Cruz TEE. 2015a - Plasmodial slime molds of a tropical karst forest, Quezon National Park, the Philippines. Pacific Science 69, 407-418.

Dagamac NHA, Rea-Maminta MAD, Batungbacal NS, Jung SH et al. 2015b - Diversity of plasmodial slime molds (myxomycetes) on coastal, mountain, and community forest of Puerto Galera, Oriental Mindoro, Philippines. Journal of Asia Pacific Biodiversity 8, 322329.

Dagamac NHA, Novozhilov YK, Stephenson SL, Lado C et al. 2017 - Biogeographical assessment of myxomycete assemblages from Neotropical and Asian Palaeotropical forest. Journal of Biogeography 44, 1524-1536.

Macabago SAB, dela Cruz TEE, Stephenson SL. 2012 - First records of myxomycetes from Lubang Island, Occidental Mindoro, Philippines. Sydowia 64, 109-118.

Macabago SAB, dela Cruz TEE, Stephenson SL. 2016 - Diversity and distribution of myxomycetes in coastal and mountain forests of Lubang Island, Occidental Mindoro, Philippines. Mycosphere 7, 18-29. 
Macabago SAB, Dagamac NHA, dela Cruz TEE, Stephenson SL. 2017 - Implications of the role of dispersal on the occurrence of litter-inhabiting myxomycetes in different vegetation types after a disturbance: A case study in the Bohol Islands, Philippines. Nova Hedwigia 104, 221236.

Novozhilov Y, Erastova DA, Shchepin ON, Shnittler M et al. 2017 - Myxomycetes associated with monsoon lowland tropical forests in southern Vietnam. Nova Hedwigia 104, 143-182.

Parente MPM, Cavalcanti LH. 2013 - Myxomycetes on Palm Trees: Species on Attalea speciosa Mart. ex Spreng. Advances in Microbiology 3, 19-23.

Pecundo MH, Dagamac NHA, Stephenson SL, dela Cruz TEE. 2017 - First myxomycetes survey in the limestone forest of Puerto Princesa Subterranean River National Park, Palawan, Philippines Nova Hedwigia 104, 129-141.

Poulain M, Meyer M, Bozonnet J. 2011 - Les Myxomycètes. Fédération mycologique et botanique Dauphiné-Savoie. Sevrier, France, 1119 p.

Rayner ADM, Boddy L. 1988 - Fungal Decomposition of Wood. Its biology and ecology. John Wiley \& Sons Ltd. Sussex, UK. 587.

Rea-Maminta MAD, Dagamac NHA, Huyop FS, Wahab RAB et al. 2015 - Comparative diversity and heavy metal biosorption of myxomycetes from forest patches on ultramafic and volcanic soils. Chemistry \& Ecology 31, 741-753.

Rojas CA, Rollins AW, Stephenson SL. 2014 - Distribution of myxomycetes among the microhabitats available for these organisms in tropical forests. In JK Misra, JP Tewari, SK Deshmukh, C Vagvoelgyi (Eds.), Fungi from different substrates. CRC Press, 126 - 143.

Schnittler M, Stephenson SL. 2002 - Inflorescences of Neotropical herbs as a newly discovered microhabitat for myxomycetes. Mycologia 94, 6-20.

Stephenson SL, Stempen H. 1994 - Myxomycetes: A Handbook of Slime Molds. Timber Press

Stephenson SL, Kalyanasundaram I, Lakhanpal T. 1993 - A comparative biogeographical study of Myxomycetes in the mid-Appalachians of eastern North America and two regions of India. Journal of Biogeography 20, 645-657.

Takahashi K. 2015 - Distribution of myxomycetes on varied leaf litter types in a mixed forest in warm- temperate Western Japan. Open Journal of Forestry 5, 686-696.

Takahashi K. 2013 - Myxomycete distribution varies among leaf litter of different vegetation in a local secondary forest of warm-temperate western Japan. Mycoscience 54, 368-377.

Tran HTM, Stephenson SL, Hyde KD, Mongkolporn O. 2008 - Distribution and occurrence of myxomycetes on agricultural ground litter and forest floor litter in Thailand. Mycologia 100, 181-190. 